\title{
Differences in allergic symptoms after the consumption of egg yolk and egg white
}

\author{
Kei Uneoka ${ }^{1 *} \mathbb{0}$, Satoshi Horino ${ }^{1}$, Ayafumi Ozaki ${ }^{1}$, Haruka Aki ${ }^{1}$, Masako Toda ${ }^{2}$ and Katsushi Miura ${ }^{1}$
}

\begin{abstract}
Hen's eggs are one of the most common causes of food allergy. Although hen's eggs are known to cause more gastrointestinal symptoms than other foods, it is not known whether there is a difference in organ-specific symptoms between egg yolk (EY) and egg white (EW). The present study aimed to determine whether there are organ-specific differences in the immediate symptoms of EY and EW in patients with hen's egg allergies. We retrospectively investigated the immediate symptoms and treatment contents of those who had a positive result in an oral food challenge (OFC) of boiled whole EY or $10 \mathrm{~g}$ of boiled EW in our hospital from January 2013 to July 2019. We compared 80 patients in the EY-OFC-positive group with 106 patients in the EW-OFC-positive group. The EY-OFC-positive group had significantly fewer respiratory symptoms and significantly more gastrointestinal symptoms than the EW-OFCpositive group and had significantly more gastrointestinal symptoms only. In terms of treatment, significantly fewer patients in the EY-OFC-positive group required beta 2-agonist inhalation, and a significantly higher proportion of patients did not require treatment. Compared to EW, EY is more likely to cause gastrointestinal symptoms and less likely to cause respiratory symptoms. It may be necessary to discriminate between EY and EW allergy during diagnosis.
\end{abstract}

Keywords: Allergens, Egg hypersensitivity, Egg yolk, Egg white, Dietary egg proteins

\section{Introduction}

Intake of hen's eggs (HE) is a common cause of food allergy in childhood [1]. Heated egg yolk (EY) contains less protein than egg white (EW) and is relatively less allergenic [2]. Most patients with HE allergy can safely consume heated EY. However, some patients exhibit immediate allergic symptoms [2]. The oral food challenge (OFC) is the gold standard diagnostic method to assess food allergy and can reproduce food allergen-induced symptoms [3]. Furthermore, complications can occur in various organs depending on the type of food consumed

*Correspondence: uneoka-k@miyagi-children.or.jp

1 Department of Allergy, Miyagi Children's Hospital, 4-3-17 Ochiai, Aoba-ku, Sendai 989-3126, Japan

Full list of author information is available at the end of the article
[4]. For example, allergic reactions to $\mathrm{HE}$ are more likely to co-exist with gastrointestinal symptoms than allergic reactions to cow's milk, soybeans, or wheat [4]. However, it remains unknown whether differences exist between symptoms induced by ingesting heated EY and EW in patients with HE allergy. Based on the allergenic differences between heated EY and EW, we hypothesized that there would be differences in organ-specific symptoms based on the ingestion of boiled EY and EW.

\section{Materials and methods}

We retrospectively analyzed the clinical backgrounds, organ-specific symptoms, and treatments in the OFCpositive groups ingesting boiled EY and EW. This study was approved by the Ethics Committee of the Miyagi Children's Hospital (approval no. 478). We obtained original author(s) and the source, provide a link to the Creative Commons licence, and indicate if changes were made. The images or other third party material in this article are included in the article's Creative Commons licence, unless indicated otherwise in a credit line to the material. If material is not included in the article's Creative Commons licence and your intended use is not permitted by statutory regulation or exceeds the permitted use, you will need to obtain permission directly from the copyright holder. To view a copy of this licence, visit http://creativecommons.org/licenses/by/4.0/. The Creative Commons Public Domain Dedication waiver (http://creativeco mmons.org/publicdomain/zero/1.0/) applies to the data made available in this article, unless otherwise stated in a credit line to the data. 
written informed consent from all participants and parents before performing the OFC.

We collected the data of patients who had positive OFC results due to ingesting boiled whole EY (approximately $16 \mathrm{~g}$ ) or $10 \mathrm{~g}$ of boiled EW at Miyagi Children's Hospital from January 2013 to July 2019. OFC was recommended in patients with a history of HE allergy or positive IgE (sIgE) specific to EY or EW. OFC was performed after obtaining informed consent from the participants. Patients were defined as having a history of allergy to $\mathrm{HE}$ if they presented with any of the following symptoms on ingestion or contact with HE: skin-mucosal symptoms (e.g., rash, swelling, pruritus, flushing, edema), respiratory symptoms (e.g., pharyngeal discomfort, nasal discharge, sneezing, coughing, wheezing, hoarseness, respiratory distress), gastrointestinal symptoms (e.g., itchy mouth, swollen lips, nausea, vomiting, diarrhea, abdominal pain), cardiovascular symptoms (e.g., hypotension), and neurological symptoms (e.g., decreased vitality, impaired consciousness). Patients with missing data or those undergoing oral immunotherapy for $\mathrm{HE}$ were excluded from the study.

All OFCs were performed in the hospital using an open method. EY and EW were strictly separated immediately after boiling at $100{ }^{\circ} \mathrm{C}$ for $20 \mathrm{~min}$. Positive OFC was defined as severe allergic reactions of grade 2 or higher according to the anaphylaxis grading score of the 2014 Japanese Guideline for Food Allergy (Table 1) [5].

Patient data, including sex, age, allergic complications, allergic history of HE, total IgE and sIgE levels (to EY, EW, and ovomucoid), immediate symptoms during OFC, and treatment details, were evaluated. Serum total $\operatorname{IgE}$ and $\operatorname{sgE}$ levels were measured within 6 months before OFC. EY or EW was administered in three divided doses $(1 / 10-3 / 10-6 / 10)$ at 30-min intervals. Stepwise OFC was performed in the following order: boiled whole EY, $1 \mathrm{~g}$ boiled EW, $10 \mathrm{~g}$ boiled EW, and boiled whole egg. EY-OFC-positive patients were not challenged to the EW-OFC. When patients accidentally ingested a tolerated amount of EY or EW and had no allergic symptoms, the lower steps of OFC were skipped. When adverse reactions occurred, patients were closely monitored. Beta 2-agonist inhalation was carried out for intermittent coughing and wheezing. Intramuscular administration of adrenaline was indicated for patients with prolonged grade 4 or higher symptoms.

Statistical analyses were performed using JMP 13 (SAS Institute Inc., Cary, NC, USA) with Fisher's exact and Wilcoxon rank-sum tests. We considered $P<0.05$ as indicating statistical significance. For sIgE levels, values $<0.34 \mathrm{U}_{\mathrm{A}} / \mathrm{mL}$ and $>100 \mathrm{U}_{\mathrm{A}} / \mathrm{mL}$ were approximated to 0.34 and 100 , respectively.

\section{Results}

We screened 84 and 135 patients with positive OFC to boiled EY (the EY-OFC-positive group) and boiled EW (the EW-OFC-positive group), respectively; finally, data from 80 and 106 patients, respectively, were analyzed (Fig. 1). The EY-OFC-positive group had a significantly lower number of patients with a history of HE ingestion than did the EW-OFC-positive group (61.3\% vs. 99.1\%) $(P<0.001)$. Serum total IgE $(394.5$ vs. $242.5 \mathrm{IU} / \mathrm{mL})$ $(P=0.007)$ and sIgE (to EY $\left[8.0\right.$ vs. $\left.2.6 \mathrm{U}_{\mathrm{A}} / \mathrm{mL}\right][P<0.001]$, EW [37.6 vs. $\left.11.8 \mathrm{U}_{\mathrm{A}} / \mathrm{mL}\right][P<0.001]$, and ovomucoid [24.2 vs. $\left.\left.6.6 \mathrm{U}_{\mathrm{A}} / \mathrm{mL}\right][P<0.001]\right)$ levels were significantly higher in the EY-OFC-positive group (Table 2).

Table 1 Classification of anaphylaxis

\begin{tabular}{|c|c|c|c|c|c|}
\hline Grade & Skin & Digestive organ & Respiratory organ & Circulatory organ & Nerve \\
\hline 1 & $\begin{array}{l}<\text { Localized }>\text { pruritus, } \\
\text { erythema, urticaria, } \\
\text { angioedema }\end{array}$ & $\begin{array}{l}\text { Oral itch and/or discomfort, } \\
\text { Swelling of lips }\end{array}$ & $\begin{array}{l}\text { Pharyngeal pruritus and/or } \\
\text { discomfort }\end{array}$ & - & - \\
\hline 2 & $\begin{array}{l}<\text { Systemic }>\text { pruritus, } \\
\text { erythema, urticaria, } \\
\text { angioedema }\end{array}$ & $\begin{array}{l}\text { Nausea, 1-2 occurrences of } \\
\text { vomiting and/or diarrhea, } \\
\text { Transient abdominal pain }\end{array}$ & $\begin{array}{l}\text { Slight nasal congestion and/ } \\
\text { or rhinorrhea, Sneezing once } \\
\text { or twice, Sporadic coughing }\end{array}$ & - & Decrease in activity level \\
\hline 3 & Above symptoms & $\begin{array}{l}\text { Repeated vomiting, and/ } \\
\text { or diarrhea, Persistent } \\
\text { abdominal Pain }\end{array}$ & $\begin{array}{l}\text { Marked nasal congestion } \\
\text { and/or rhinorrhea, Repeated } \\
\text { sneezing, Persistent cough, } \\
\text { Laryngeal pruritus }\end{array}$ & $\begin{array}{l}\text { Tachycardia (increased } \geq 15 \\
\text { beats/min) }\end{array}$ & Sense of unease \\
\hline 4 & Above symptoms & Above symptoms & $\begin{array}{l}\text { Laryngeal tightness, } \\
\text { Wheezing, Dyspnea, } \\
\text { Hoarseness, Barking cough, } \\
\text { Cyanosis, Dysphagia }\end{array}$ & $\begin{array}{l}\text { Arrhythmia, Decreased blood } \\
\text { pressure }\end{array}$ & Unrest, fear of death \\
\hline 5 & Above symptoms & Above symptoms & Respiratory arrest & $\begin{array}{l}\text { Severe bradycardia, Marked } \\
\text { decrease in blood pressure, } \\
\text { Cardiac arrest }\end{array}$ & Unconsciousness \\
\hline
\end{tabular}




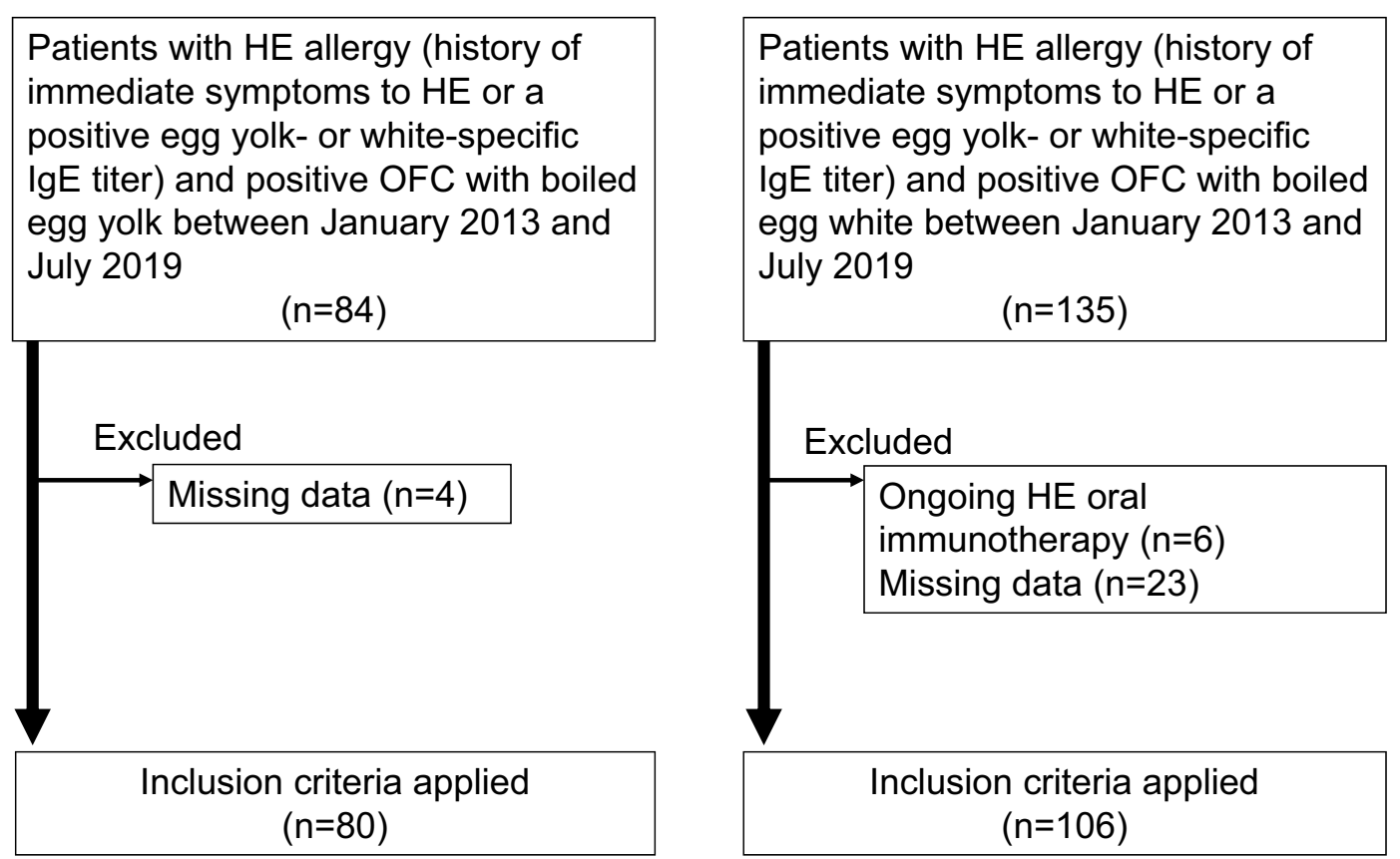

Fig. 1 Schematic representation of the study participants' dispositions. HE hen's egg, OFC oral food challenge

Table 2 Characteristics of participants

\begin{tabular}{lllr}
\hline & Positive OFC with boiled egg yolk & Positive OFC with boiled egg white & $P$-value \\
\hline Number & 80 & 106 & $72(67.9 \%)$ \\
Male (\%) & $59(73.8 \%)$ & $3.5(2.1-5.1)$ & 0.421 \\
Age (years) & $3.3(1.7-4.9)$ & $66(62.2 \%)$ & 0.359 \\
Atopic dermatitis (\%) & $49(61.3 \%)$ & $31(29.2 \%)$ & 1.000 \\
Bronchial asthma (\%) & $24(30.3 \%)$ & $105(99.1 \%)$ & 1.000 \\
History of egg ingestion (\%) & $49(61.3 \%)$ & $76(71.7 \%)$ & $<0.001$ \\
Immediate egg allergy history (\%) & $51(63.8 \%)$ & $24(22.6 \%)$ & 0.270 \\
Anaphylactic egg allergy history (\%) & $10(12.5 \%)$ & $242.5(105.0-640.5)$ & 0.087 \\
Total lgE (IU/mL) & $394.5(175.5-1279.5)$ & $2.6(0.9-7.9)$ & 0.007 \\
Egg yolk-specific lgE $\left(\mathrm{U}_{\mathrm{A}} / \mathrm{mL}\right)$ & $8.0(3.9-15.7)$ & $11.8(5.9-31.9)$ & $<0.001$ \\
Egg white-specific $\operatorname{lgE}\left(\mathrm{U}_{\mathrm{A}} / \mathrm{mL}\right)$ & $37.6(17.9-74.1)$ & $6.6(1.9-19.2)$ & $<0.001$ \\
Ovomucoid-specific $\lg E\left(\mathrm{U}_{\mathrm{A}} / \mathrm{mL}\right)$ & $24.2(9.2-47.2)$ & $<.001$ \\
\hline
\end{tabular}

Data are presented as the median (interquartile range) or number (\%). Statistical analyses were performed using Wilcoxon rank sum test or Fisher's exact test. Serum levels of egg yolk-, egg white-, and ovomucoid-specific lgE were measured by ImmunoCAP assay (Thermo Fisher Scientific, Uppsala, Sweden)

IgE immunoglobulin E, OFC oral food challenge

The EY-OFC-positive group also had significantly more gastrointestinal symptoms $(70.0 \%$ vs. $55.7 \%)(P=0.049)$, especially diarrhea (22. $5 \%$ vs. $11.3 \%)(P=0.046)$, and significantly fewer respiratory symptoms $(22.5 \%$ vs. $37.8 \%)(P=0.037)$ than the EW-OFC-positive group (Table 3).

A higher proportion of patients in the EY-OFCpositive group had only gastrointestinal symptoms $(36.3 \%$ vs. $20.8 \%)(P=0.021)$ than did those in the
EW-OFC-positive group. The EY-OFC-positive group had a lower proportion of patients treated with beta 2-agonist inhalation $(10.0 \%$ vs. $25.5 \%)(P=0.008)$ and a significantly higher proportion of patients without medical treatment $(35.0 \%$ vs. $20.8 \%)(P=0.044)$ than the EW-OFC-positive group. In the EY-OFC-positive group, patients with only gastrointestinal symptoms $(n=29)$ were significantly older than patients without gastrointestinal symptoms $(\mathrm{n}=24)(4.9$ vs. 2.4 years, 
Table 3 Symptoms, anaphylaxis severity scores, and treatments administered to participants with positive oral food challenge results

\begin{tabular}{|c|c|c|c|}
\hline & Positive OFC with boiled egg yolk & Positive OFC with boiled egg white & $P$-value \\
\hline Number & 80 & 106 & \\
\hline \multicolumn{4}{|l|}{ Symptoms } \\
\hline Skin (\%) & $44(55.0 \%)$ & $73(68.9 \%)$ & 0.066 \\
\hline Respiratory (\%) & $18(22.5 \%)$ & $40(37.8 \%)$ & 0.037 \\
\hline Cardiovascular (\%) & $0(0.0 \%)$ & $0(0.0 \%)$ & 1.000 \\
\hline Neurologic (\%) & $3(3.8 \%)$ & $8(7.5 \%)$ & 0.356 \\
\hline Gastrointestinal (\%) & $56(70.0 \%)$ & $59(55.7 \%)$ & 0.049 \\
\hline Abdominal pain (\%) & $30(37.5 \%)$ & $34(32.1 \%)$ & 0.533 \\
\hline Nausea or vomiting (\%) & $27(33.8 \%)$ & $31(29.2 \%)$ & 0.527 \\
\hline Diarrhea (\%) & $18(22.5 \%)$ & $12(11.3 \%)$ & 0.046 \\
\hline Gastrointestinal only (\%) & $29(36.3 \%)$ & $22(20.8 \%)$ & 0.021 \\
\hline Anaphylaxis (\%) & $4(5.0 \%)$ & $10(9.4 \%)$ & 0.401 \\
\hline \multicolumn{4}{|l|}{ Anaphylaxis severity score } \\
\hline Grade $2(\%)$ & $53(66.3 \%)$ & $60(56.6 \%)$ & 0.225 \\
\hline Grade $3(\%)$ & $22(27.5 \%)$ & $33(31.1 \%)$ & 0.629 \\
\hline Grade 4 (\%) & $5(6.3 \%)$ & $13(12.3 \%)$ & 0.214 \\
\hline Grade 5 (\%) & $0(0.0 \%)$ & $0(0.0 \%)$ & 1.000 \\
\hline \multicolumn{4}{|l|}{ Treatment } \\
\hline Antihistamines (\%) & $45(56.3 \%)$ & $73(68.9 \%)$ & 0.091 \\
\hline Inhalation of $\beta_{2}$ stimulant (\%) & $8(10.0 \%)$ & $27(25.5 \%)$ & 0.008 \\
\hline Transfusion (\%) & $2(2.5 \%)$ & $0(0.0 \%)$ & 0.184 \\
\hline Steroid (\%) & $4(5.0 \%)$ & $2(1.9 \%)$ & 0.405 \\
\hline Adrenaline (\%) & $1(1.3 \%)$ & $0(0.0 \%)$ & 0.430 \\
\hline No treatment (\%) & $28(35.0 \%)$ & $22(20.8 \%)$ & 0.044 \\
\hline
\end{tabular}

Data are presented as number (\%)

OFC oral food challenge

respectively) $(P=0.001)$. However, there was no significant difference in the total IgE and sIgE levels (to EY, EW, and ovomucoid) between the two groups. In the EY-OFC-positive group $(n=29)$, the median time for gastrointestinal symptoms to appear from the first intake of EY was $120 \mathrm{~min}$. None of the EY-OFC-positive groups met the diagnostic criteria of the international consensus guidelines for the diagnosis and management of food protein-induced enterocolitis syndrome (FPIES) [6].

\section{Discussion}

The major allergens of EW include ovomucoid and ovalbumin. Ovomucoid is known to be heat resistant. On the contrary, ovalbumin is known to be sensitive to thermal denaturation, and thus its allergenicity is decreased by heating. Furthermore, an in vitro study on the allergenic changes of EW proteins compared fried EW, boiled EW (at $100{ }^{\circ} \mathrm{C}$ for 10 or $30 \mathrm{~min}$ ), and baked EW at $170{ }^{\circ} \mathrm{C}$ [7]. The study showed that neither the temperature nor the duration of heat treatment reduced the antigenicity of ovomucoid [7]. However, they reported that IgE reactivity to ovalbumin was at its lowest when EW was boiled for $30 \mathrm{~min}$, and that allergenicity was also reduced [7]. In our study, we boiled $\mathrm{HE}$ at $100{ }^{\circ} \mathrm{C}$ for $20 \mathrm{~min}$. Similar to the previous report, the allergenicity of EW was likely decreased [7]. In preparing EY-OFC, EY were separated from EW immediately after boiling to minimize contamination by EW proteins. The amount of HE proteins present in boiled whole EY was minimal [2]. Therefore, allergens of EW might have had little effect on the reactivity of EY in the EY-OFC-positive group.

The proportion of patients with gastrointestinal symptoms among OFC-positive patients was higher for whole eggs than for other foods $[4,8]$. In this study, the EY-OFC-positive group had significantly more gastrointestinal symptoms than the EW-OFC-positive group. The results of previous studies, as well as our findings, suggest that whole eggs are more likely to cause gastrointestinal symptoms than other foods, and consuming $\mathrm{EY}$ is more likely to cause gastrointestinal symptoms than consuming EW.

We previously reported that EY-OFC-positive patients had delayed HE tolerance acquisition, and it 
may be possible to estimate HE allergy prognosis by administering EY-OFC [9]. The major allergens in IgEmediated EY allergy are thought to be chicken serum albumin (Gal d 5) and YGP42 (Gal d 6) [10]. However, it remains unclear whether it is these major EY allergens or other EY components that provoke gastrointestinal symptoms in EY-OFC-positive patients. To the best of our knowledge, this is the first study to report the differences in clinical symptoms induced by boiled EY and EW in patients with HE allergy. Our results may be useful for predicting the appearance of organ-specific symptoms when EY-OFC shows a positive result.

This study had some limitations. First, psychogenic reactions might affect subjective symptoms when using the open OFC method. Second, the retrospective nature of the study may have led to selection bias.

In conclusion, this study found that boiled EY was more likely to provoke gastrointestinal than respiratory symptoms compared to boiled EW in patients with HE allergy. Furthermore, HE allergy may include EY allergy and EW allergy separately.

\section{Abbreviations}

HE: Hen's egg; EY: Egg yolk; EW: Egg white; OFC: Oral food challenge; slgE: Specific IgE; FPIES: Food protein-induced enterocolitis syndrome; Gal d 5: Chicken serum albumin; Gal d 6: YGP42.

\section{Acknowledgements}

The authors thank Ms. Miho Shikama for her support in OFC and dietary advice for the patients. They also thank Editage (www.editage.jp) for assisting with English language editing.

\section{Authors' contributions}

$\mathrm{KU}$ designed the study and wrote the manuscript. $\mathrm{SH}, \mathrm{AO}, \mathrm{HA}$, and $\mathrm{KM}$ were involved in revising the manuscript. MT was involved in critical review. All authors read and approved the final manuscript.

\section{Funding}

This work was supported by MHLW Health, Labour and Welfare Sciences Research Grants, Research on Immunologic and Allergic Diseases Program Grant Number 19FE1001.

\section{Availability of data and materials}

Not applicable.

\section{Declarations}

\section{Ethics approval and consent to participate}

This study was approved by the Ethics Committee of the Miyagi Children's Hospital (approval no. 478). We obtained written informed consent from all participants and parents before enrollment in the study.

\section{Consent for publication}

All participants gave their consent to publish clinical data.

\section{Competing interests}

The authors declare that they have no competing interests.

\section{Author details}

${ }^{1}$ Department of Allergy, Miyagi Children's Hospital, 4-3-17 Ochiai, Aoba-ku, Sendai 989-3126, Japan. ${ }^{2}$ Laboratory of Food and Biomolecular Science, Graduate School of Agricultural Science, Tohoku University, Sendai, Japan.

Received: 7 July 2021 Accepted: 7 September 2021

Published online: 25 September 2021

\section{References}

1. Caubet J-C, Kondo Y, Urisu A, Nowak-Węgrzyn A. Molecular diagnosis of egg allergy. Curr Opin Allergy Clin Immunol. 2011;11:210-5.

2. Yanagida N, Sato S, Asaumi T, Ogura K, Borres MP, Ebisawa M. Safety and feasibility of heated egg yolk challenge for children with egg allergies. Pediatr Allergy Immunol. 2017:28:348-54.

3. Muraro A, Werfel T, Hoffmann-Sommergruber K, Roberts G, Beyer K, Bindslev-Jensen $C$, et al. EAACI food allergy and anaphylaxis guidelines: diagnosis and management of food allergy. Allergy. 2014;69:1008-25.

4. Ahrens B, Niggemann B, Wahn U, Beyer K. Organ-specific symptoms during oral food challenge in children with food allergy. J Allergy Clin Immunol. 2012;130:549-51.

5. Urisu A, Ebisawa M, Ito K, Aihara Y, Ito S, Mayumi M, et al. Japanese guideline for food allergy 2014. Allergol Int. 2014;63:399-419.

6. Nowak-Węgrzyn A, Chehade M, Groetch ME, Spergel JM, Wood RA, Allen $\mathrm{K}$, et al. International consensus guidelines for the diagnosis and management of food protein-induced enterocolitis syndrome: executive summary - Workgroup Report of the Adverse Reactions to Foods Committee, American Academy of Allergy, Asthma \& Immunology. J Allergy Clin Immunol. 2017;139:1111-26.

7. Shin M, Han Y, Ahn K. The influence of the time and temperature of heat treatment on the allergenicity of egg white proteins. Allergy Asthma Immunol Res. 2013:5:96-101.

8. Gupta M, Grossmann L, Spergel J, Cianferoni A. Egg food challenges are associated with more gastrointestinal reactions. Children. 2015;2:371-81.

9. Horino S, Kitazawa H, Satou T, Miura K. Hyperresponsiveness to boiled egg yolk in early life leads to prolonged egg allergy. Allergy Asthma Immunol Res. 2019;11:433-7.

10. Dhanapala P, De Silva C, Doran T, Suphioglu C. Cracking the egg: An insight into egg hypersensitivity. Mol Immunol. 2015;66:375-83.

\section{Publisher's Note}

Springer Nature remains neutral with regard to jurisdictional claims in published maps and institutional affiliations.

\footnotetext{
Ready to submit your research? Choose BMC and benefit from:

- fast, convenient online submission

- thorough peer review by experienced researchers in your field

- rapid publication on acceptance

- support for research data, including large and complex data types

- gold Open Access which fosters wider collaboration and increased citations

- maximum visibility for your research: over 100M website views per year

At BMC, research is always in progress.

Learn more biomedcentral.com/submissions
} 